\title{
A Scoping Review and Appraisal of AAC Research in Inclusive School Settings
}

\author{
Teresa lacono $^{1}$ (D) . Juliet Goldbart ${ }^{2}$ (D) Sarah N. Douglas ${ }^{3}$ (D) \\ Ana Garcia-Melgar ${ }^{4}$ (D)
}

Accepted: 19 January 2022 / Published online: 21 February 2022

(c) The Author(s) 2022

\begin{abstract}
The aim of this scoping review was to explore the extent to which AAC studies have occurred in inclusive versus segregated settings, the role of AAC in inclusive setting studies, and the evidence for AAC supporting inclusive education of students with complex communication needs. A scoping review of studies published from 2000 to 2020 that involved students who used or could benefit from AAC or their peers conducted within schools yielded 167 studies. Relatively few studies $(n=28,17 \%)$ were conducted in inclusive settings. Data from these 28 studies were extracted and appraised for quality. AAC was integrated into intervention in 57\% of these studies and in $61 \%$ improved use of AAC was an outcome variable, but in only six was this the main aim. Eighty-two students who used or could benefit from AAC were participants across studies. Classroom peers participated across 11 studies, including those in which qualitative designs were employed. The strength of evidence for the role of AAC could not be determined because only 12 studies were experimental and addressed varied aims. Nonetheless, these and seven qualitative studies were appraised as being of high quality. Implications of findings are discussed in terms of extending the evidence to demonstrate the role of AAC, and its potential to support academic and social school inclusion of students with complex communication needs, which may not rely on proficient use of AAC.
\end{abstract}

Keywords Augmentative and alternative communication - Scoping review · Inclusive education · Peer interaction - Complex communication needs · Academic skills

Acknowledged as a human right (United Nations, 2006), there has been international commitment to ensuring Education for All (EFA) children, regardless of individual or social determinants that can lead to educational inequalities (UNESCO, 2015).

Extended author information available on the last page of the article 
Unfortunately, inclusive education remains elusive for children with extensive support needs, including those with complex communication needs, whose speech does not meet daily functional needs. Many children, globally, miss out on education altogether or are restricted to segregated settings (Inclusion International, 2009), not only in middle and low income (Hui et al., 2018; Sharma et al., 2019), but also high income countries (Iacono et al., 2019; Wehmeyer et al., 2020).

For students with complex communication needs, which is often associated with severe disability or high support needs (Mirenda, 2014), augmentative and alternative communication (AAC) has offered a potential means to support both their social and academic inclusion in school education (Beukelman \& Mirenda, 2012; Calculator, 2009). Yet, despite a burgeoning of research into ways in which AAC can support access to high quality education for students with complex communication needs, a question remains regarding the extent to which this research has been conducted in inclusive settings. Mirenda (2014), in reflecting on progress from 1992 to 2012 and citing data and/or reports from the United States (US), Canada, and the United Kingdom (UK), noted that relatively few of these students were likely to spend their days in general education classrooms. For those students who did, it was evident that simple presence in a general education classroom "does not insure that a student's academic and/or social needs will be met, or that students who require AAC will be provided with appropriate communication systems/devices that are supported in optimal ways" (Mirenda, 2014, p. 21).

The original model of participation that has guided AAC assessment and intervention (Beukelman \& Mirenda, 2012) offered much hope for reducing the exclusion of students with complex communication needs from regular school settings. In this Participation Model, there is an emphasis on removing opportunity barriers, thereby closely aligning it with contemporary understanding of the social model of disability, whereby reasonable adjustments are made to address the needs of individuals, thereby enabling inclusion (Shakespeare, 2018). Included in the Participation Model is also consideration of access opportunities in terms of a person's capacities and communication needs. In contrast, the social model of disability places a greater focus on acknowledging the human rights of all people to be afforded equal opportunity, and less on requiring individuals to change (e.g., through developing skills) to reduce their experience of disability and exclusion (UNICEF, 2012). According to UNESCO, educational inclusion is the "process of addressing and responding to the diversity of needs of all learners through increasing participation in learning, cultures and communities, and reducing exclusion within and from education" (UNICEF, 2012, p. 8). Further aligned with the social model is an emphasis on reasonable adjustments to curriculum content, practices and structures, and strategies enabling accommodation to learner needs (UNICEF, 2012), rather than expecting the learner to achieve certain prerequisite skills before being given access to the same educational opportunities as their peers without disability.

The notion of removing prerequisites that form barriers to participation and learning within real and functional contexts drove early inroads in providing people with complex communication needs accessible means of communication (Reichle \& Karlan, 1985), which was later captured in the Participation Model (Beukelman \& Mirenda, 2012). Hence, there has been an historical ambition within the AAC field 
to increase participation of people with complex communication needs, including in educational settings, which reflects the aspiration of full inclusion (Calculator, 2009). Yet true inclusion has long been recognised as difficult to achieve, with Calculator (2009) noting challenges in balancing opportunities to develop skills in using AAC and increasing a student's communicative competence with being fully included in a classroom and with class peers. Questions remain regarding the extent to which AAC supports inclusive education and the experience of inclusion by students who use AAC.

The aim of this study was to conduct a scoping review of research to determine the role of AAC in supporting students with complex communication needs, especially those with high support needs, in inclusive educational settings, and in accessing curriculum and the social milieu of schools. With EFA as a Millennium Development Goal (UNESCO, 2000, 2015), the year 2000 was selected as a starting point for the review in addressing the following questions:

1. To what extent has AAC research been conducted in inclusive (or mainstream) as contrasted with segregated settings for students in the years of compulsory education?

2. What has been the role of AAC in research conducted in inclusive school education settings?

3. What is the evidence for AAC supporting inclusive education?

\section{Methods}

\section{Design}

We followed Arksey and O'Malley's (2005) scoping review framework to address the research questions, and a quality appraisal of studies to address Research Question 3. Details of the protocol can be found in Iacono et al. (2018). Methodological quality was guided by the PRISMA Extension for Scoping Reviews (PRISMA ScR) checklist (Tricco et al., 2018).

In brief, a search was conducted within PsycINFO (OVID), CINAHL (UBESCO), and Proquest (Australia \& NZ Database, Education Collection-including ERIC, Nursing \& Allied Health, Psychology, Social Science). Search terms were: "AAC," "complex communication needs," "intervention," "disability," "school children," "school education," and their variations (e.g., terms used for the target population included "Down* syndrome," "intellectual disability," "autism," "autism spectrum," "cerebral palsy," "severe motor impairment," and those for AAC included specific forms, such as "communication boards," "speech generating devices," "signs," "sign language," and "graphic symbols"). The inclusion criteria were designed to capture studies (a) that were empirical, peer-reviewed and published in journals; (b) with participants who were children with complex communication needs (i.e., who lacked functional speech associated with a developmental disability) or school students who interacted with them, and of compulsory school age; (c) in which some form of AAC 
was used as part of an intervention, or by participants during data collection or within the school in which data were collected; and (d) conducted in a school context. The initial search captured studies conducted from January 2000 to September, 2017 then repeated to extend the search to December, 2019. Hand searches were conducted in the journal, Augmentative and Alternative Communication, and of reference lists of included studies. Forward citations were conducted in August, 2020 in Web of Science of studies included from the database search, providing studies published beyond 2019.

\section{Study Selection}

Studies from the database search were imported into Endnote ${ }^{\mathrm{TM}}$ and then Covidence (n.d.) for screening. Studies found from the hand and forward citations searches were imported into Endnote, then screened. The first author and at least one other author completed all title, abstract, and full-text screening. Disagreements were resolved through discussion. The results are presented in Fig. 1 (Moher et al., 2009), showing 167 studies that met selection criteria.

\section{Categorizing Studies and Data Extraction}

To determine the extent to which studies had been conducted in mainstream versus segregated settings (Research Question 1), studies were coded as inclusive or segregated. Inclusive studies were conducted in mainstream (also known as general education) schools or classrooms. Segregated studies were those in which data collection occurred in special schools or classrooms (including those located in mainstream

Fig. 1 PRISMA flow chart

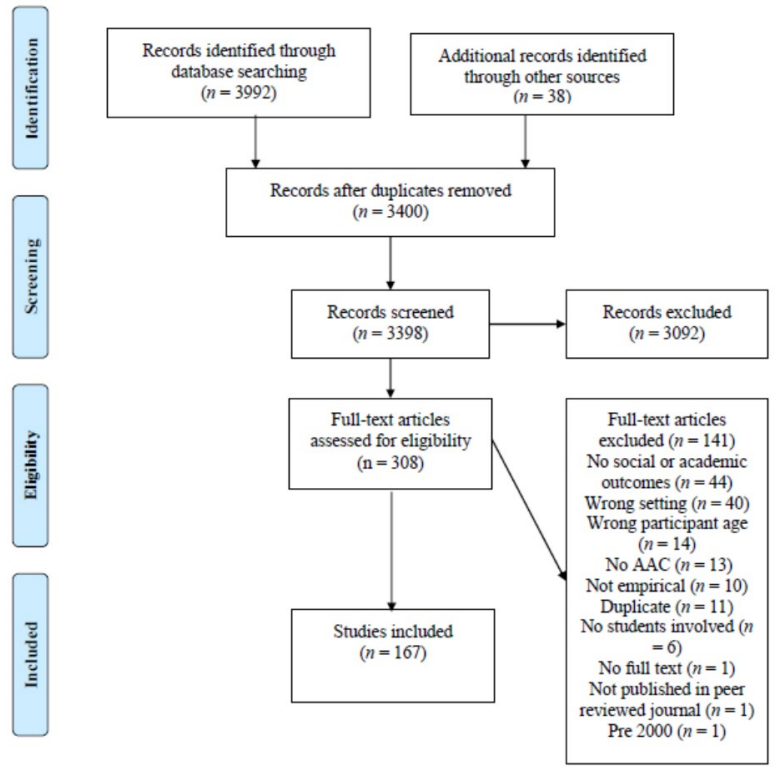


schools), or where students were withdrawn to a separate room for data collection with no interaction with class peers (e.g., a resource or therapy room) or attempt to document generalization to the classroom or peer interactions. Mixed setting studies were those in which one or more participants was from an inclusive and a segregated setting for data collection. At least two authors completed this categorization at the full-text screening stage, with decisions reviewed when data were extracted, then again when a quality appraisal was conducted for inclusive setting studies (see below).

To address Research Question 2 (role of AAC in inclusive education), the following data were extracted for each study conducted in an inclusive setting or across mixed settings where data from the inclusive setting could be extracted: country, study aims, participant details (student number, gender, disability, age; adult number and roles), predominant research design, role of AAC and key findings. This information is presented in Table 1.

\section{Quality Assessment}

A quality appraisal was completed for the studies with inclusive settings to address Research Question 3 (the evidence for AAC supporting inclusive education). This appraisal was included to provide an indication of quality, of relevance to questions about the strength of evidence. Given the anticipated variation in designs (i.e., quantitative, qualitative, and mixed), studies were appraised using the Mixed Methods Appraisal Tool (MMAT, Pluye et al., 2011). Using this tool, studies are appraised for quality indicators for each design, with two initial questions used to screen for further appraisal: a "No" response to either indicated a non-empirical study (e.g., clinical case descriptions), which was excluded from further appraisal. Applying the MMAT to 31 studies, Pace et al. (2012) obtained moderate to perfect agreement between raters across MMAT criteria.

The first and last author completed the appraisals. They first independently assessed three studies (qualitative, mixed-methods, and Single Case Experimental Designs - SCED), agreeing on 11 of 15 criteria, then resolving disagreements through discussion. Decisions were made about modifications for certain designs: (a) for Criterion 1.3 (qualitative) potential concerns that could affect rigor and trustworthiness were noted; (b) Criterion 3.1 (non-randomized quantitative designs) was adapted to assess whether participants were described in sufficient detail in order to accommodate SCED (Barlow et al., 1984); and (c) for Criterion 4.2 (quantitative descriptive), "Not applicable" was indicated for participants being representative of the target population to accommodate non-experimental single case studies (e.g., $\mathrm{AB}$ and other designs in which potential confounds are not controlled). Independent appraisal of remaining studies yielded 90\% agreement (range 80-97\% across designs). Disagreements were resolved through discussion.

\section{Data Synthesis}

To synthesize key characteristics of inclusive setting studies, categories for the country, aims, and research design were developed and assigned a numerical code 


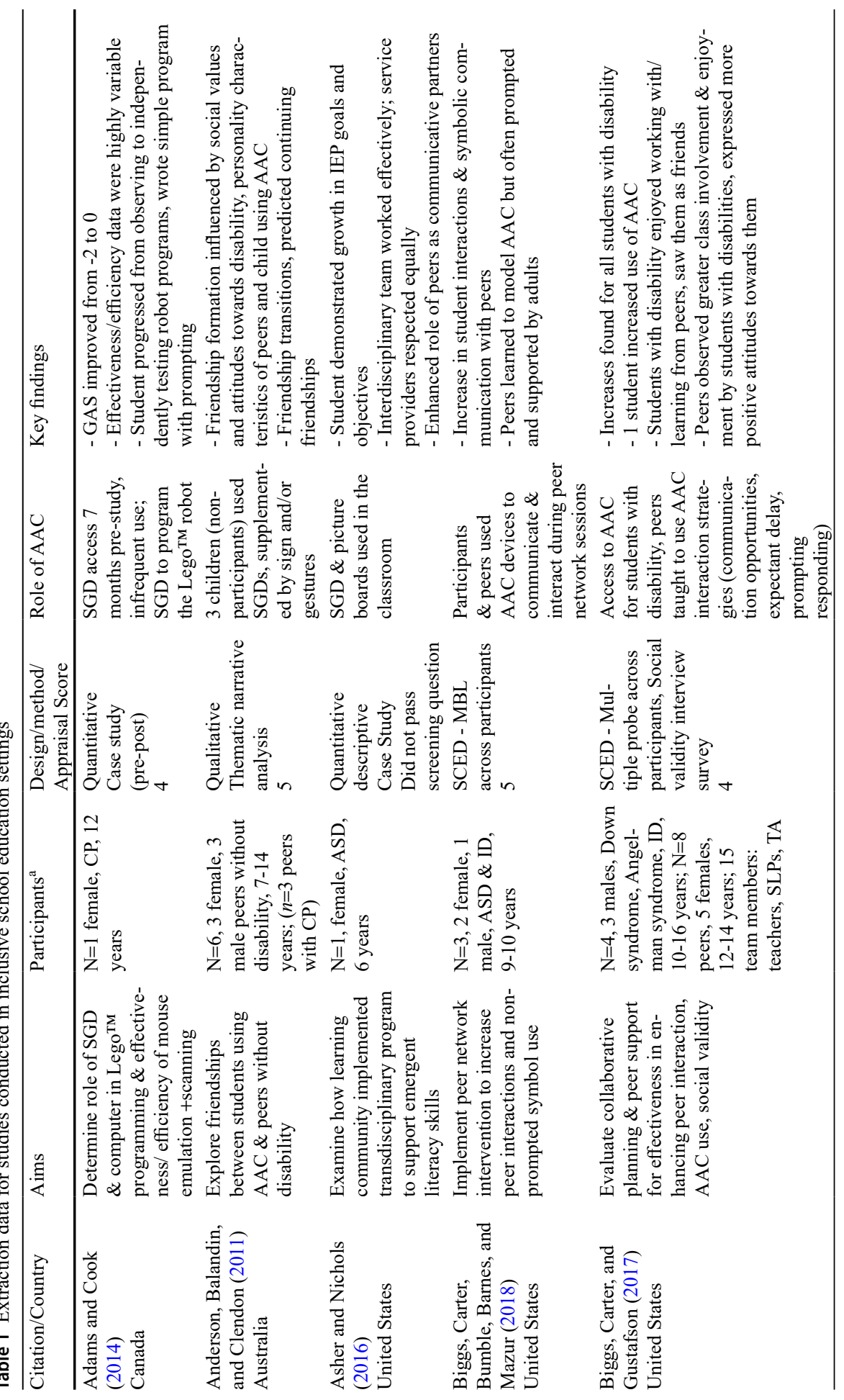




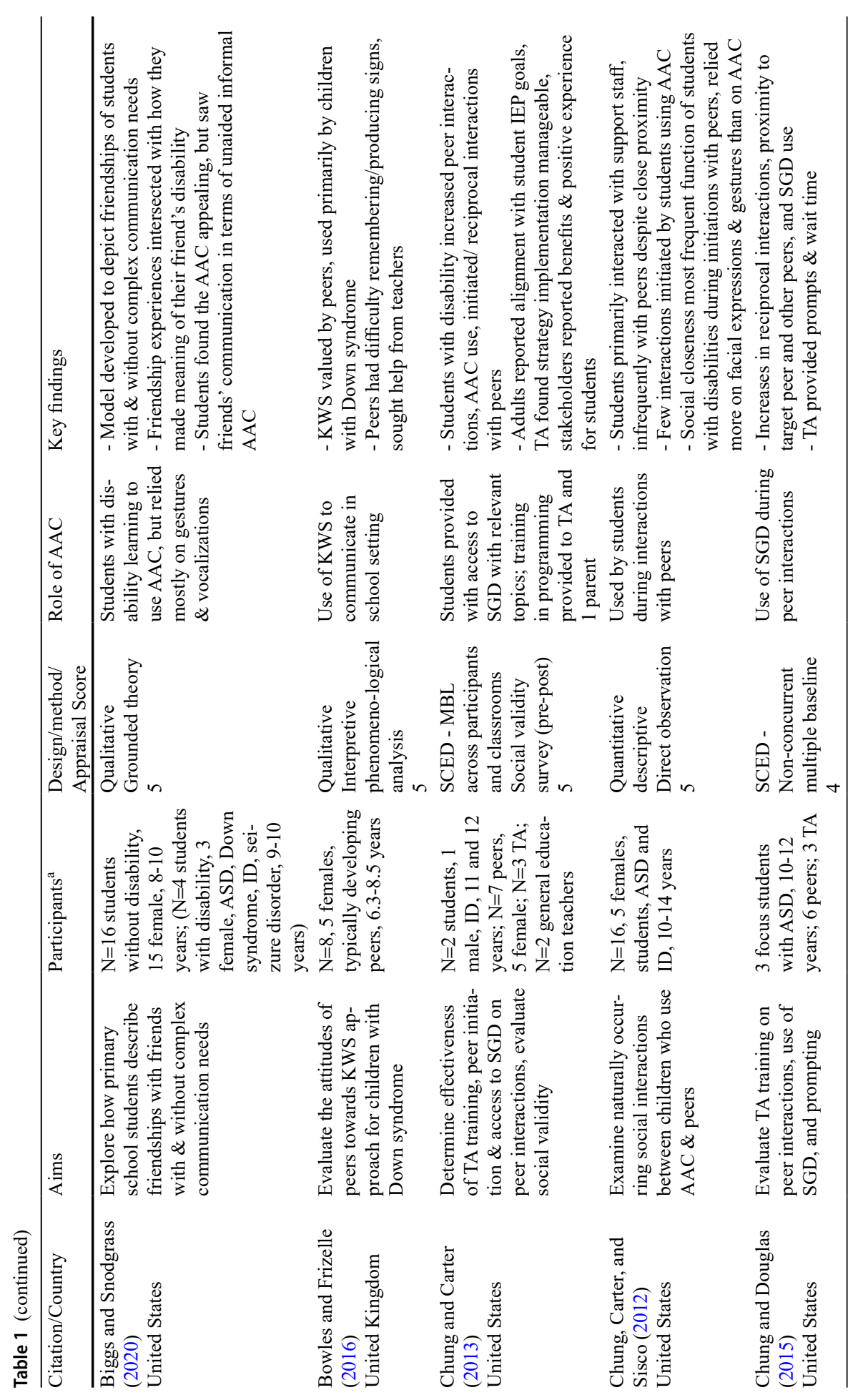




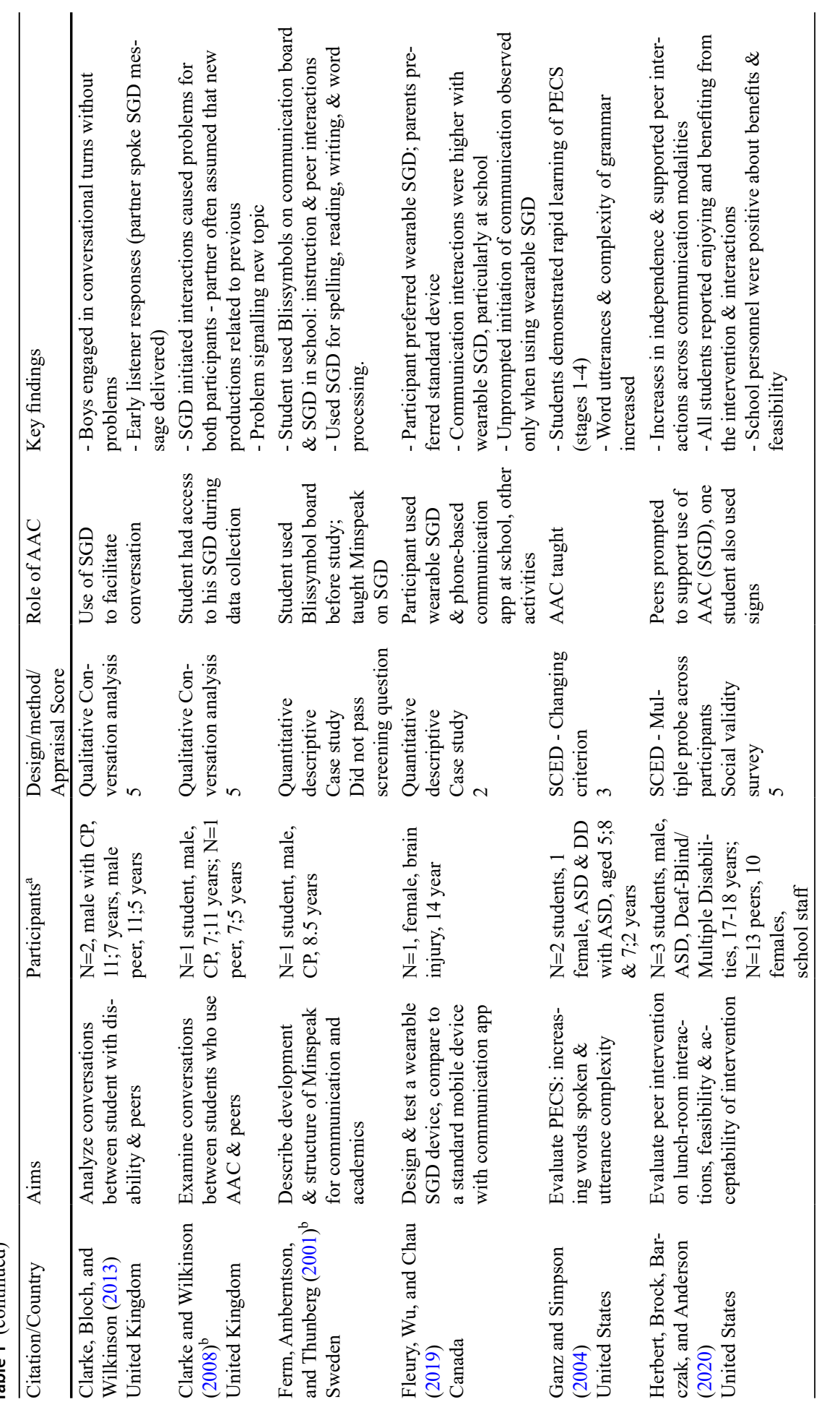




\begin{tabular}{|c|c|c|c|c|c|c|}
\hline & 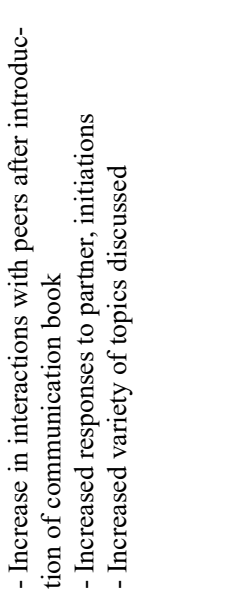 & 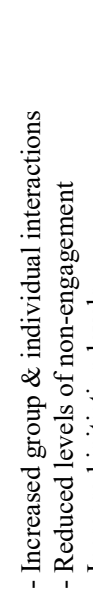 & 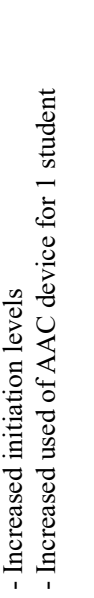 & 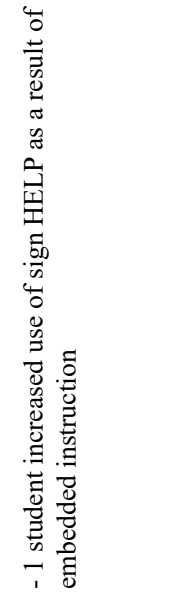 & 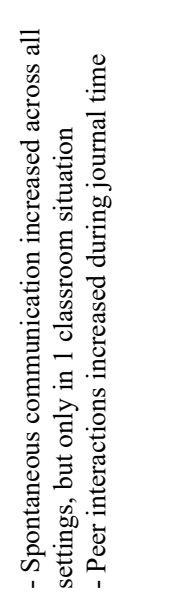 & 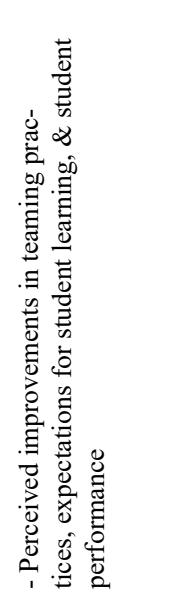 \\
\hline & 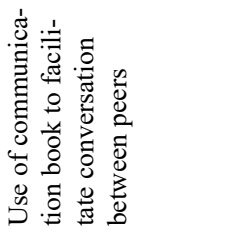 & 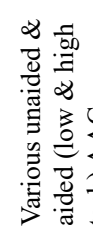 & & 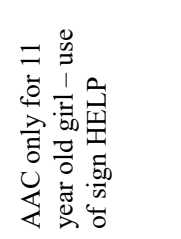 & 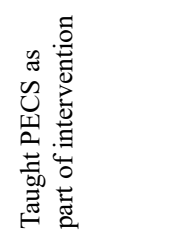 & 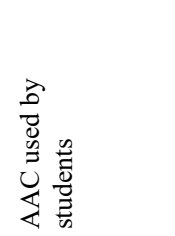 \\
\hline 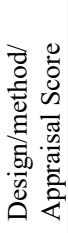 & 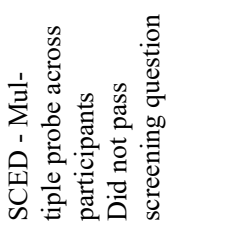 & 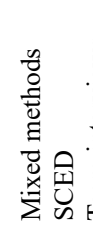 & & 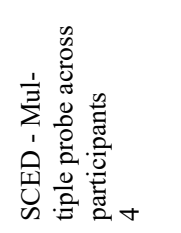 & 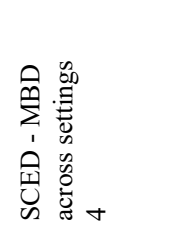 & 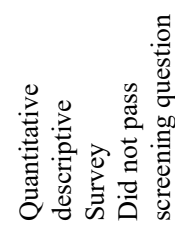 \\
\hline & 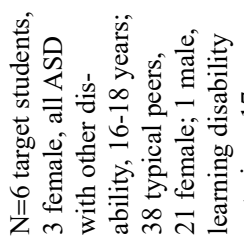 & 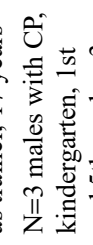 & 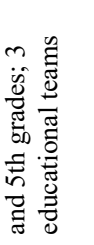 & 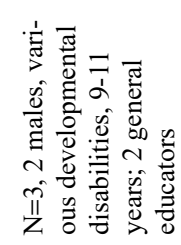 & 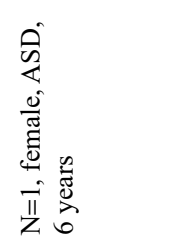 & 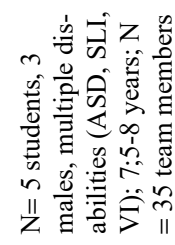 \\
\hline 妾 & 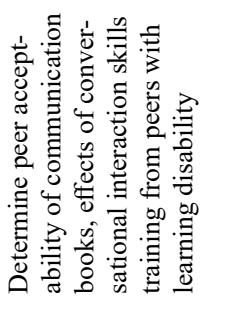 & 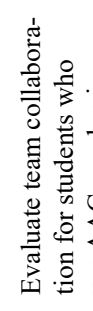 & 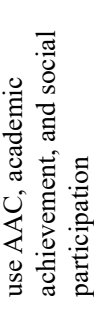 & 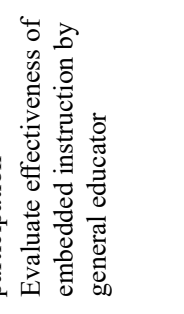 & 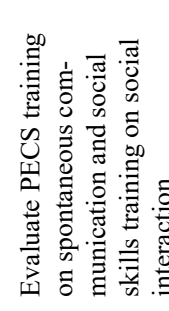 & 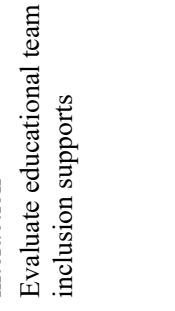 \\
\hline 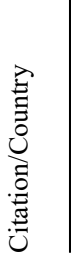 & 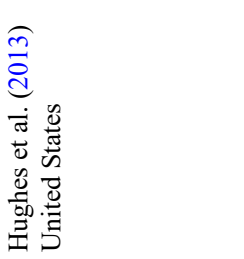 & 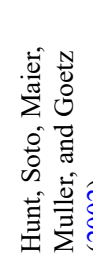 & 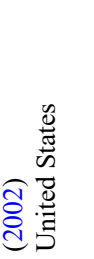 & 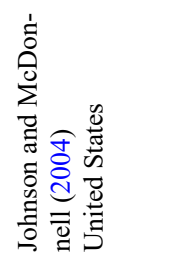 & 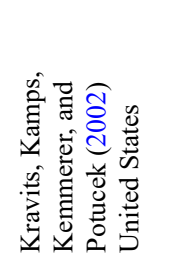 & 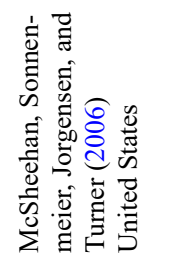 \\
\hline
\end{tabular}




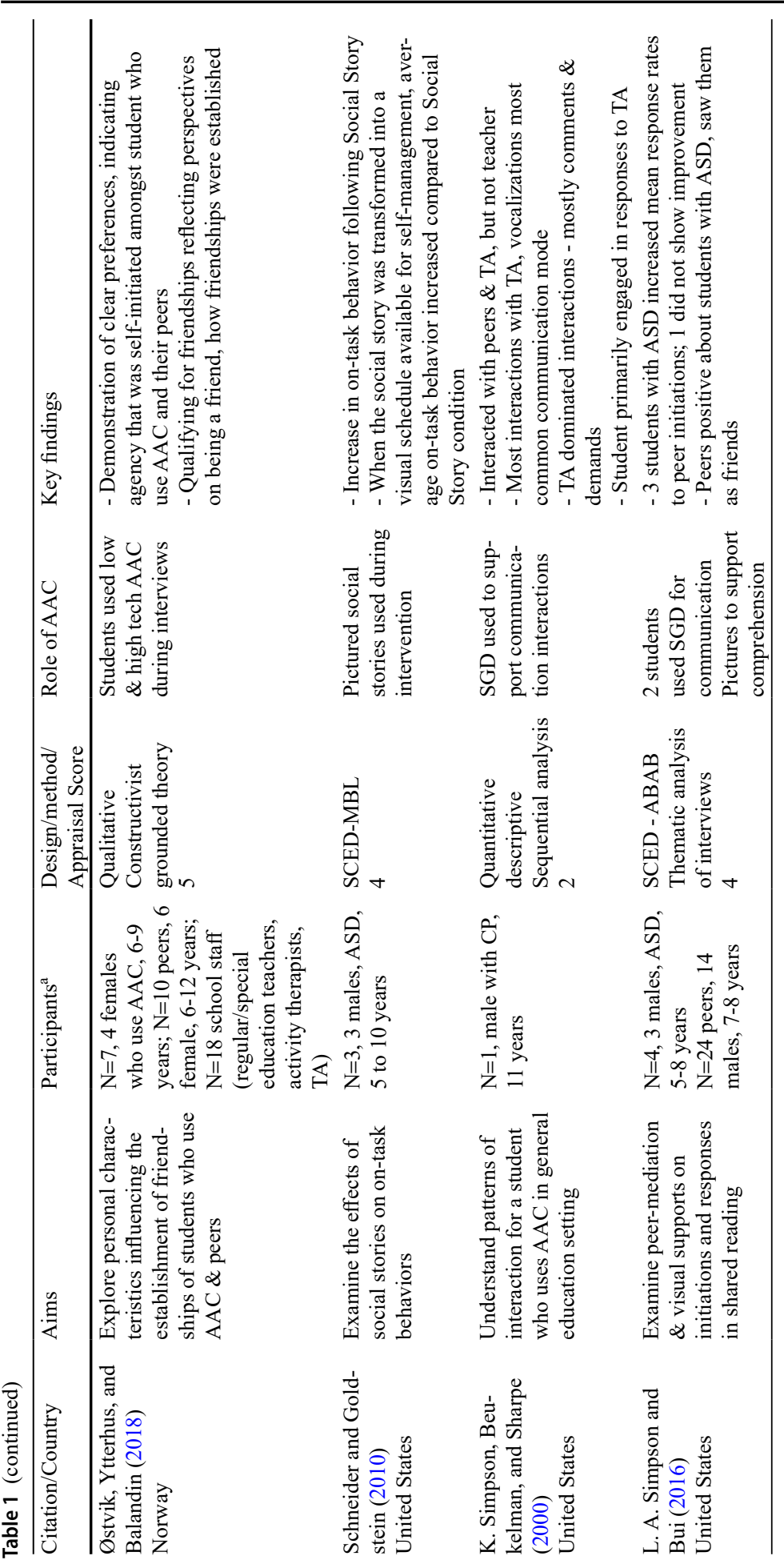




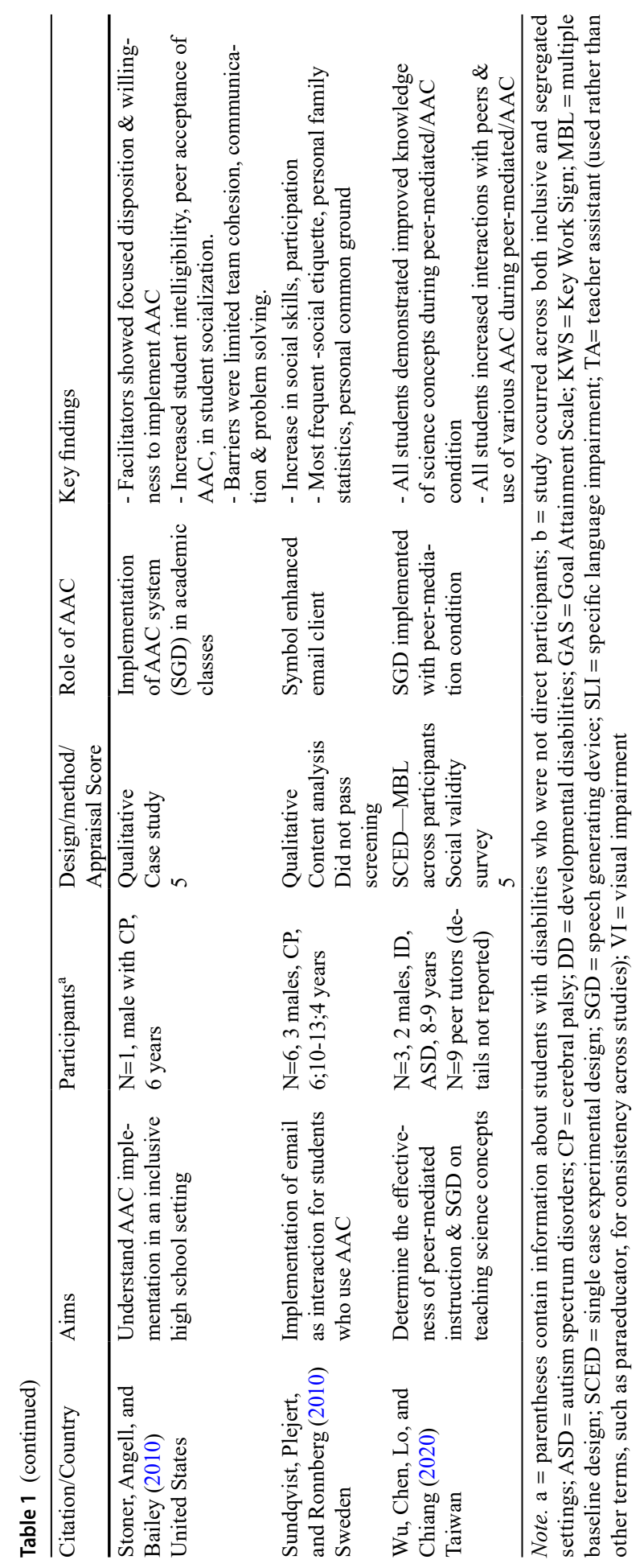


for entry into IBM SPSS Statistics 25. Variables were created for the type of AAC used by participants (either as participant description or an intervention component): that is, unaided (signs or gestures), aided low tech (aids in which no electronics are involved, such as communication boards or books) and aided high tech (aids in which electronics are involved, such as iPads or dedicated devices). Tallies of these categories informed the scope of research across school education settings.

\section{Results}

The number of studies conducted across inclusive, segregated, or mixed settings was tallied to address Research Question 1: To what extent has AAC research been conducted in inclusive (or mainstream) as contrasted with segregated settings for students in the years of compulsory education? Data extracted within inclusive settings addressed Research Question 2: What has been the role of AAC in research conducted in inclusive school education settings? This data extraction combined with the qualitative appraisal, addressed Research Question 3: what is the evidence for AAC supporting school inclusion?

\section{School Setting}

Of the 167 included studies, 26 (15.6\%) were conducted in inclusive settings, 129 (77.2\%) in segregated settings, and $12(7.2 \%)$ across segregated and inclusive settings (categorized as mixed). For three of the mixed setting studies, some data collection occurred in a non-school setting, usually at home; for the remaining studies, data collection occurred in both segregated and inclusive settings, but the inclusive setting data could be disaggregated for only two. These two studies are included in Table 1 with data extraction of relevance to the inclusive setting only (in both cases, this was for students who attended only mainstream schools). Results from studies conducted in segregated settings are reported elsewhere (Iacono et al., 2022).

\section{Characteristics of Inclusive Setting Studies and Role of AAC}

The 28 studies in Table 1 were conducted across seven countries and published in English. Although the initial intention was to include studies published in other languages, none were found through the search process. Most studies $(n=18,64 \%)$ were conducted in the US. Following in frequency, $11 \%(n=3)$ were conducted in the UK, $7 \%(n=2)$ each in Canada and Sweden, and 4\% $(n=1)$ each in Australia, Norway, and Taiwan.

The role of AAC was explored by examining study aims, and where relevant, independent and dependent variables, as well as student participant characteristics. In $57 \%$ of studies $(n=16)$, the teaching of or access to AAC was the main intervention component (e.g., Ganz \& Simpson, 2004) or part of a multicomponent intervention (e.g., Biggs et al., 2018). In 61\% $(n=17)$, AAC was a dependent variable in quantitative studies (e.g., Chung \& Douglas, 2015) or a variable of interest in qualitative studies (e.g., Clarke \& Wilkinson, 2008). 
The types of AAC used by or taught to students varied, with aided forms dominating. Although the use of unaided AAC (signs) was referred to in $32 \%$ of studies $(n=9)$, in only one did it feature: Bowles and Frizelle (2016) examined the attitudes of class peers to the use of Key Word Sign by students with Down syndrome. More often, use of sign was limited in the few studies in which it was reported: for example, in one study, a student increased her use of HELP following an intervention of embedded instruction (Johnson \& McDonnell, 2004). Access to or use of low tech AAC included communication books (e.g., Hughes et al., 2013) or other ways of displaying graphic symbols, such as strips as often used with the Picture Exchange Communication System (PECS) (e.g., Kravits et al., 2002) or were used as visual supports, such as in pictured social stories (Schneider \& Goldstein, 2010). High tech AAC, mostly speech generating devices (SGD), such as applications on an iPad ${ }^{\mathrm{TM}}$ and dedicated devices, were incorporated into or used by participants to varying extents across $75 \%(n=21)$ of studies. In some studies, they were one of multiple AAC systems: for example, Hunt et al. (2002) included three students who used or had previously used different forms of AAC.

Although AAC featured in many intervention studies, in only six was the aim to improve AAC use (Table 1). In three studies, it was the sole aim: these were to examine the efficacy of the PECS (Ganz \& Simpson, 2004) and access to AAC (Stoner et al., 2010), and compare across types of high tech AAC in terms of student preferences and interactions (Fleury et al., 2019). Often, improved AAC use was targeted in addition to other aims: Examples were improving peer interactions (Biggs et al., 2018; Biggs et al., 2017; Kravits et al., 2002), which featured in 10 (36\%) studies, with peers also being mediators of the intervention in two (Herbert et al., 2020; Simpson \& Bui, 2016). Peers also featured in three studies about friendships experienced by students with complex communication needs (Anderson et al., 2011; Biggs \& Snodgrass, 2020; Østvik et al., 2018). Peers also featured in studies examining perceptions of, or attitudes towards AAC as used by fellow-students (Bowles \& Frizelle, 2016; Hughes et al., 2013). In six studies (21\%), academic skills were taught and incorporated the use of AAC, including those relating to literacy (e.g., reading, spelling) (Asher \& Nichols, 2016; Ferm et al., 2001), robot programming (Adams \& Cook, 2014) and science concepts (Wu et al., 2020). Relatedly, Schneider and Goldstein (2010) examined the role of pictured social stories in improving on-task behaviour to enhance academic participation. Less frequent were studies in which the roles of adults, in particular teachers, teaching assistants (referred to using various terms across studies) and speech language pathologist, were explored in terms of effective and collaborative teams in classrooms in which AAC was integrated (Asher \& Nichols, 2016; Hunt et al., 2002; McSheehan et al., 2006). Also explored were the roles of general education teachers to support academic learning for one student increasing her sign for HELP following embedded instruction (Johnson \& McDonnell, 2004). In addition, the outcomes of training teacher assistants to support use of AAC, peer interactions and academic learning were examined (Chung \& Carter, 2013; Chung \& Douglas, 2015).

Across studies, 82 students with disability were primary participants. In most studies $(n=22,78 \%)$, they were selected on the basis of using or requiring AAC, but were not necessarily described as being proficient in its use; Biggs et al. (2017), for 
example, noted that prior to the study, one participant required prompting to use his SGD, which he refused to use outside of a therapy session, as did another participant. In fact, the extent to which AAC use was functional prior to study participation was usually difficult to determine from descriptions. The number of students with disability as participants ranged from 1 to 16 ( mean $=3.3$, mode $=1$ ) across the 28 studies. The small participant sample numbers may reflect the predominance of SCED ( $n=13$, including one mixed methods) to evaluate intervention efficacy. No other experimental designs were used in inclusive setting studies. Rather, quantitative descriptive studies (including $\mathrm{AB}$ designs) were used to document improvements in targeted skills. In addition to use of SCED, peer interactions were explored through qualitative designs $(n=4)$, as were friendships $(n=2)$, and to explore access to $(n=1)$ and perceptions of AAC $(n=1)$.

Overall, classroom peers participated across 11 studies, numbering from 1 to 38 (mean $=12.6$, mode $=6$ ). The largest sample of peers participated in a study into classroom peer acceptance of communication books and support of conversations: interactions of any of 38 peers with 6 students with disability were compared across a multiple baseline (across students with disability) design (Hughes et al., 2013). In three studies, only peers participated, but in these, their friendships with (Anderson et al., 2011; Biggs \& Snodgrass, 2020) and attitudes towards students who used AAC

Table 2 Descriptions of study aim categories

\begin{tabular}{|c|c|}
\hline Category & Description \\
\hline $\begin{array}{l}\text { Communication } \\
\text { skills }\end{array}$ & $\begin{array}{l}\text { Increases in communication through AAC, } \\
\text { including learning to use one or more types } \\
\text { of AAC }\end{array}$ \\
\hline Access to AAC & $\begin{array}{l}\text { Improve or provide access to one or more } \\
\text { types of AAC }\end{array}$ \\
\hline $\begin{array}{l}\text { Compare across } \\
\text { AAC }\end{array}$ & $\begin{array}{l}\text { Compare outcomes across two or more AAC } \\
\text { modalities or systems }\end{array}$ \\
\hline Academic skills & $\begin{array}{l}\text { Improve skills relating to curriculum, such as } \\
\text { spelling, reading, numeracy or mathematics }\end{array}$ \\
\hline Peer interaction & $\begin{array}{l}\text { Improve or evaluate aspects of interactions } \\
\text { with classroom peers by students who use } \\
\text { AAC }\end{array}$ \\
\hline Peer mediation & $\begin{array}{l}\text { Examine the effect of interventions or } \\
\text { strategies delivered by classroom peers on } \\
\text { the communication and/or interactions of } \\
\text { students using AAC }\end{array}$ \\
\hline Perceptions of AAC & $\begin{array}{l}\text { Explore attitudes and responses to the use of } \\
\text { AAC, most often by peers of students using } \\
\text { AAC }\end{array}$ \\
\hline Adult training & $\begin{array}{l}\text { Examine the effect of training adults (usually } \\
\text { teachers or paraprofessionals) on the com- } \\
\text { munication of students using AAC }\end{array}$ \\
\hline Team effectiveness & $\begin{array}{l}\text { Effects on communication of team focused } \\
\text { on supporting students use of AAC. }\end{array}$ \\
\hline Friendships & $\begin{array}{l}\text { How friendships between students who } \\
\text { use AAC and their classrooms peers were } \\
\text { formed or their characteristics }\end{array}$ \\
\hline
\end{tabular}


in their classes (Bowles \& Frizelle, 2016) were sought. In these studies, the students who used AAC were not direct participants (see Tables 1 and 2).

\section{Quality Appraisal}

The MMAT results are summarised in Table 3. Five studies were excluded as they did not pass one or both screening questions: further appraisal was completed for the other 23 studies. The effectiveness of AAC in achieving targeted outcomes was explored in 12 SCED (the only experimental designs) studies (including in one mixed

Table 3 Frequency of studies scoring "yes" on each criteria of the mixed methods appraisal tool (n=24)

\begin{tabular}{|c|c|}
\hline Qualitative Criteria & Yes \\
\hline \multicolumn{2}{|l|}{ Qualitative $(n=7)^{\mathrm{a}}$} \\
\hline 1.1. Is the qualitative approach appropriate to answer the research question? & 7 \\
\hline 1.2. Are the qualitative data collection methods adequate to address the research question? & 7 \\
\hline 1.3. Are the findings adequately derived from the data? & 7 \\
\hline 1.4. Is the interpretation of results sufficiently substantiated by data? & 7 \\
\hline 1.5. Is there coherence between qualitative data sources, collection, analysis and interpretation? & 7 \\
\hline \multicolumn{2}{|l|}{ 3. Quantitative non-Randomized $(\mathrm{n}=1)^{\mathrm{a}}$} \\
\hline 3.1. Are the participants representative of the target population? & 1 \\
\hline 3.2. Are measurements appropriate regarding both the outcome and exposure/intervention? & 1 \\
\hline 3.3. Are there complete outcome data? & 1 \\
\hline 3.4. Are the confounders accounted for in the design and analysis? & 0 \\
\hline 3.5. During the study period, is the intervention/exposure administered as intended? & 0 \\
\hline \multicolumn{2}{|l|}{ 3a. Quantitative Experimental Single Case Designs $(n=11)^{a}$} \\
\hline 3.1. Are the participants described with sufficient detail? & 10 \\
\hline 3.2. Are measurements appropriate regarding both the outcome and exposure/intervention? & 9 \\
\hline 3.3. Are there complete outcome data? & 10 \\
\hline 3.4. Are the confounders accounted for in the design and analysis? & 9 \\
\hline 3.5. During the study period, is the intervention/exposure administered as intended? & 8 \\
\hline \multicolumn{2}{|l|}{ 4. Quantitative Descriptive $(n=3)$} \\
\hline 4.1. Is the sampling strategy relevant to address the research question? & 2 \\
\hline 4.2. Is the sample representative of the target population? & $0(\mathrm{NA})$ \\
\hline 4.3. Are the measurements appropriate? & 3 \\
\hline 4.4. Is the risk of nonresponse bias low? & 2 \\
\hline 4.5. Is the statistical analysis appropriate to answer the research question? & 3 \\
\hline
\end{tabular}

5. Mixed methods $(\mathrm{n}=1)$

5.1. Is there an adequate rationale for using a mixed methods design to address the research 1 question?

5.2. Are the different components of the study effectively integrated to answer the research 0 question?

5.3. Are the results adequately brought together into overall interpretations?

5.4. Are divergences and inconsistencies between quantitative and qualitative results ad- $\quad 0$ equately addressed?

5.5. Do the different components of the study adhere to quality criteria of each tradition of the 1 methods involved?

$\mathrm{a}=$ excludes studies that fell into the category but did not pass screening questions, hence were not appraised further 
methods study). Of these, one study did not pass the screening questions as a result of having a number of objectives that were not clearly structured around specific research questions or aims (Hughes et al., 2013). Of the remaining 11 SCED, the number that met each MMAT criterion ranged from 8 to 10 . The most frequent problems were with reporting of fidelity measures or outcomes, such as in two studies in which PECS was the independent variable (perhaps because it is a manualised program) (Ganz \& Simpson, 2004; Kravits et al., 2002). In addition, control was not demonstrated in one study: Ganz and Simpson (2004) did not include a baseline, noting the reason was to adhere to the program, but as a result, control was lost; Schneider and Goldstein (2010) did not achieve a stable baseline for one participant in a multiple baseline design.

Closer examination of the aims and findings of the SCED studies (Table 1) shows a focus on peers in terms of improving social interactions with students who used AAC in six studies (e.g., Biggs et al., 2018; Hughes et al., 2013), with four also addressing peer mediation on interactions and, in some cases, the student with disability's use of AAC (e.g., Biggs et al., 2017; Herbert et al., 2020; Wu et al., 2020). In considering the potential benefits of school inclusion in both enhancing the extent to which students who use AAC become part of the social milieu and can access the curriculum, the study by $\mathrm{Wu}$ et al. (2020) is noteworthy. In this SCED study, the effect of peer mediated instruction and access to an SGD programmed to contain relevant academic vocabulary was demonstrated in terms of increased knowledge of science concepts, peer interactions and use of various AAC modalities.

Although only experimental studies can directly address the extent to which AAC is effective in supporting inclusion, studies of social/ conversational interactions and friendships provided insight into the role of AAC. These studies were largely of high quality, with only one failing to meet the screening criteria (Sundqvist et al., 2010), and the others meeting all qualitative design criteria. In these studies, friendships between students who used AAC and their general classroom peers featured (Anderson et al., 2011; Biggs \& Snodgrass, 2020; Østvik et al., 2018). Biggs and Snodgrass (2020) compared friendship formation between students who used speech and those in which one friend used AAC. In friendship formation, some students tended not to rely on their AAC, but rather their extant pre-symbolic communication, such as vocalizations, gestures and facial expression. Similarly, Østvik et al. (2018) found that AAC played a limited role in establishing friendships, although parents and teachers gave it greater prominence, believing student competence in using AAC demonstrated their agency. Rather, opportunities to spend time together and share activities (academic and social) were found to support affinity through recognising shared characteristics and time for intimacy (Biggs \& Snodgrass, 2020), and experiencing reciprocal benefits from the friendship (Anderson et al., 2011).

\section{Discussion}

Findings from this review indicate that research into AAC for school aged students with complex communication needs is firmly established in segregated settings, where over $80 \%$ of studies published over the period of 2000-2020 in English were 
conducted. Of the 28 studies of students within inclusive settings, most were from the US, perhaps reflecting its large population and that it dominates research into the education of students with disabilities, more broadly: In the review of studies conducted in segregated settings, for example, almost half were conducted in the US, with the remainder from across 15 other countries (Iacono et al., 2022). The US was also early to introduce legislation intended to realise the human right to education for students with disability in environments considered least restrictive (Wehmeyer et al., 2020). Such legislation has provided a model for other countries more recently committed to inclusive education (Wu et al., 2020).

The reason for situating most research in segregated settings could well reflect an ongoing resistance to full school inclusion of students with extensive support needs, such that they remain in special schools or classrooms that are separate from the mainstream, and hence, from peers without disabilities (Wehmeyer et al., 2020). This possibility was evident in the study by Anderson et al. (2011) in which they noted difficulties with recruitment because "... few children with severe cerebral palsy who used an SGD could be found within the mainstream education system" (p. 89). More recent studies reflect a similar dominance of segregated settings, such that even in inclusive setting studies, it was apparent that many students spent much of their school days in special education classrooms or resource units (e.g., Herbert et al., 2020). Often, their time with peers was limited: it may have occurred regularly (e.g., Schneider \& Goldstein, 2010), but for varying amounts of the school day (Biggs \& Snodgrass, 2020) or mainly for the purposes of data collection (e.g., Biggs et al., 2018).

In terms of the scope of the inclusive school setting research and regardless of the time spent in the inclusive setting, classroom peers played a central role. They were often direct participants in order to better understand (a) conversations between students who used AAC and classmates (Clarke et al., 2013; Clarke \& Wilkinson, 2008); (b) how they could support the social and academic inclusion of students (e.g., Simpson \& Bui, 2016), including shifting this role from teachers (Wu et al., 2020) or teacher assistants (Biggs et al., 2017); and (c) their friendships with students with complex communication needs, who may or may not have used AAC functionally or efficiently (Anderson et al., 2011; Østvik et al., 2018).

The focus on peers was motivated in a number of studies by concerns about stigma (Anderson et al., 2011; Bowles \& Frizelle, 2016) or poor attitudes towards students who use AAC (Bowles \& Frizelle, 2016) and their social isolation arising from most interactions occurring with adults rather than classroom peers (Chung et al., 2012). Even students with complex communication needs who relied on pre-symbolic means were found in one study to increase interactions with peers through training provided by teacher assistants or peers (Biggs et al., 2018). The reliance on non-symbolic communication or speech that was difficult to understand was sometimes the result of a lack of vocabulary on AAC systems that would enable formulating the most appropriate message in a peer interaction, which did pose challenges for peer-AAC user conversations (Anderson et al., 2011). Yet, competence in AAC use may be of greater concern to adults, such as parents and teachers (Østvik et al., 2018; Stoner et al., 2010), than to students. From the perspective of students, being part of the same academic and social activities that provided opportunities for sustained engagement 
was found to be more central to forming and sustaining friendships (Biggs \& Snodgrass, 2020).

Within the inclusive education settings, students did need to navigate the differences in interactions associated with complex communication needs and reliance on AAC. Observational studies have shown that students with disabilities tend to interact more with adults than peers in the classroom (Chung et al., 2012; Simpson et al., 2000) or to take a passive role with peers (Chung et al., 2012). Further, the nature of conversations between students with complex communication needs relying on AAC and their speaking peers was found, through detailed conversational analysis (Clarke et al., 2013; Clarke \& Wilkinson, 2008), to differ in certain aspects from those between speaking peers. Peers were able to accommodate these differences, however, such as by repetition of messages delivered through the SGD (Clarke et al., 2013). Still, differences were also found in the nature of friendships or how they were formed, but Biggs and Snodgrass (2020) argued that these friendships were of no lesser quality than those between speaking peers.

The 12 appraised studies that were experimental (i.e., SCED) or included an experimental component (39\%) addressed varied aims, making synthesis of outcomes from the different interventions difficult. Most did meet key criteria required to demonstrate rigor, providing empirical evidence that, within inclusive school settings, students could be taught to increase their communication (Kravits et al., 2002) and academic skills (Wu et al., 2020) through access to AAC. Furthermore, intervention targeting interactions, whether delivered by adults (e.g., Chung \& Douglas, 2015) or peers (Biggs et al., 2017; Wu et al., 2020) could increase the reciprocity of interactions between peers with and without disability, as could interventions providing access to AAC (Kravits et al., 2002).

\section{Implications}

The results of this review show the potential of AAC in supporting inclusive education of students who use or stand to benefit from AAC. Because studies in which students were removed from the classroom or interactions with peers to learn use of AAC, without generalization data collected within these contexts, the extent to which direct interventions are needed to teach its use first remains unclear. Wu et al. (2020) provided an example in which such removal from the natural setting of the classroom did not occur. They found that peers could be effective mediators in supporting the use of SGD by students with complex communication needs who had no previous AAC experience, while teaching science concepts (the dependent variable). Students in this study increased their use of SGD as well as non-AAC communication following intervention, with the added benefit of increased peer interactions. Further, studies relying on observational and qualitative methods provided outcomes that might call into question an assumption that students need to be effective users of AAC before they can become part of the social milieu of the classroom and form friendships with classroom peers: that is, that gains in AAC use can be made when intervention occurs in the classroom or with class peers in various school activities. Close examination of the SCED and the qualitative studies shows that opportunities to be fully included enable students with and without disability to share social spaces, 
which, in turn provide the chance to work out each other's communication (Biggs \& Snodgrass, 2020) and what they bring to the friendship (Anderson et al., 2011; Østvik et al., 2018). These friendships do look different, but there is evidence of accommodation, such that children can learn "to better understand their friend's idiosyncratic communication forms" (Biggs \& Snodgrass, 2020, p. 91).

These findings point to a key tenet in AAC practice to disregard prerequisite models in favour of one in which students are supported to participate within the environments they choose, as reflected in the Participation Model (Beukelman \& Mirenda, 2012). Hence, rather than supporting the use of AAC within segregated settings or withdrawing students from classrooms to teach communication skills, the potential for AAC to support inclusion is perhaps better realized by observations of students and their peers within inclusive classrooms, then providing the supports that facilitate full educational and social inclusion on the basis of those observations. Building the research base for this approach will rely on future studies that combine non-experimental (e.g., natural observations, qualitative) with experimental intervention studies, with both situated within the inclusive classroom or other school environment.

\section{Limitations}

The search strategy failed to yield studies published in languages other than English, which met inclusion criteria. It is possible that the search terms were not sensitive to variations in other languages, or that the databases did not capture non-English papers, resulting in a bias towards English-speaking countries. A solution may be stakeholder consultations, as recommended as optional for scoping reviews by Arskey and O'Malley (2005). Furthermore, extending the search to include grey literature, typically sourced through non-commercial publications (White et al., 2013), such as on government or organizational websites or in academic library repositories, may have resulted in greater international representation and avoided potential bias towards studies in which there have been significant or positive findings. Of course, inclusion of grey literature requires additional scrutiny in a review of peerreviewed studies because of a lack of quality control or criteria for publication that vary within those journals (White et al., 2013). Reaching out to the international community in AAC to identify terms, and databases and other sources is recommended for future reviews. The findings of this scoping review could also inform a more narrowly focused systematic review of experimental studies or synthesis of qualitative research that address specific outcomes. Exploring peer interactions and friendships for students with complex communication needs may prove fruitful in efforts to better understand the role of AAC in supporting educational inclusion.

A further limitation was that it was not always clear if students met criteria for either complex communication needs or high support needs. This problem was partly the result of differences in participant description details provided and partly a lack of agreed definitions and specific operational criteria for either characteristic. In our attempts to ensure all relevant studies were captured and address the research questions, over-inclusion may have ensued. 


\section{Conclusions}

The findings of this research synthesis show that, since 2000, AAC research in schools has occurred largely in segregated settings. The findings from a minority of studies conducted in mainstream schools and classrooms suggest that the potential for AAC to support inclusive education of students with complex communication needs can perhaps best be realized through enhanced opportunities for shared experiences and interactions with peers without disability. Research into the most effective forms of AAC and methods to support communication continue to have a place in evidencebased education and practice, but perhaps not at the expense of full school inclusion of students with complex communication needs.

Funding Open Access funding enabled and organized by CAUL and its Member Institutions

\section{Declarations}

Ethical Approval This study did not involve human or non-human participation and therefore, ethical approval was not required.

Informed Consent Informed consent was not obtained because this study did not involve human participants.

Conflict of Interest The authors declare no conflict of interest.

Open Access This article is licensed under a Creative Commons Attribution 4.0 International License, which permits use, sharing, adaptation, distribution and reproduction in any medium or format, as long as you give appropriate credit to the original author(s) and the source, provide a link to the Creative Commons licence, and indicate if changes were made. The images or other third party material in this article are included in the article's Creative Commons licence, unless indicated otherwise in a credit line to the material. If material is not included in the article's Creative Commons licence and your intended use is not permitted by statutory regulation or exceeds the permitted use, you will need to obtain permission directly from the copyright holder. To view a copy of this licence, visit http:/creativecommons.org/ licenses/by/4.0/.

\section{References}

Adams, K., \& Cook, A. (2014). Programming and controlling robots using scanning on a speech generating communication device: A case study. Technology and Disability, 26(1), 49-59. https://doi. org/10.3233/TAD-140404

Anderson, K., Balandin, S., \& Clendon, S. (2011). "He cares about me and I care about him." Children's experiences of friendship with peers who use AAC. Augmentative and Alternative Communication, 27(2), 77-90. https://doi.org/10.3109/07434618.2011.577449

Arksey, H., \& O’Malley, L. (2005). Scoping studies: Towards a methodological framework. International Journal of Social Research Methodology, 8(1), 19-32.https://doi.org/10.1080/1364557032000119616

Asher, A., \& Nichols, J. D. (2016). Collaboration around facilitating emergent literacy: Role of occupational therapy. Journal of Occupational Therapy, Schools, and Early Intervention, 9(1), 51-73. https://doi.org/10.1080/19411243.2016.1156415

Barlow, D., Hayes, S., \& Nelson, R. (1984). The scientist practitioner: Research and accountability in clinical and educational settings. Pergamon Press

Beukelman, D., \& Mirenda, P. (2012). Augmentative and alternative communication: Supporting children and adults with complex communication needs (4th ed.). Paul H. Brookes 
Biggs, E. E., Carter, E. W., Bumble, J. L., Barnes, K., \& Mazur, E. L. (2018). Enhancing peer network interventions for students with complex communication needs. Exceptional Children, 85(1), 66-85. https://doi.org/10.1177/0014402918792899

Biggs, E. E., Carter, E. W., \& Gustafson, J. (2017). Efficacy of peer support arrangements to increase peer interaction and AAC use. American Journal on Intellectual and Developmental Disabilities, 122(1), 25-48. https://doi.org/10.1352/1944-7558-122.1.25

Biggs, E. E., \& Snodgrass, M. R. (2020). Children's perspectives on their relationships with friends with and without complex communication needs. Research and Practice for Persons with Severe Disabilities, 45(2), 81-97. https://doi.org/10.1177/1540796919901271

Bowles, C., \& Frizelle, P. (2016). Investigating peer attitudes towards the use of key word signing by children with Down syndrome in mainstream schools. British Journal of Learning Disabilities, 44(4), 284-291. https://doi.org/10.1111/bld.12162

Calculator, S. N. (2009). Augmentative and alternative communication (AAC) and inclusive education for students with the most severe disabilities. International Journal of Inclusive Education, 13(1), 93-113. https://doi.org/10.1080/13603110701284656

Chung, Y. C., \& Carter, E. W. (2013). Promoting peer interactions in inclusive classrooms for students who use speech-generating devices. Research and Practice for Persons with Severe Disabilities, 38(2), 94-109. https://doi.org/10.2511/027494813807714492

Chung, Y. C., Carter, E. W., \& Sisco, L. G. (2012). Social interactions of students with disabilities who use augmentative and alternative communication in inclusive classrooms. American Journal on Intellectual and Developmental Disabilities, 117(5), 349-367. https://doi.org/10.1352/1944-7558-117.5.349

Chung, Y. C., \& Douglas, K. H. (2015). A peer interaction package for students with autism spectrum disorders who use speech-generating devices. Journal of Developmental and Physical Disabilities, 27(6), 831-849. https://doi.org/10.1007/s10882-015-9461-1

Clarke, M., Bloch, S., \& Wilkinson, R. (2013). Speaker transfer in children's peer conversation: Completing communication-aid-mediated contributions. Augmentative and Alternative Communication, 29(1), 37-53. https://doi.org/10.3109/07434618.2013.767490

Clarke, M., \& Wilkinson, R. (2008). Interaction between children with cerebral palsy and their peers 2: Understanding initiated VOCA-mediated turns. Augmentative and Alternative Communication, 24(1), 3-15. https://doi.org/10.1080/07434610701390400

Covidence.org. Covidence systematic review software [Computer software]. http://www.covidence.org

Ferm, U., Amberntson, B., \& Thunberg, G. (2001). Development and evaluation of a Minspeak application using Blissymbols: Experiences from two case studies. Augmentative and Alternative Communication, 17(4), 233-244

Fleury, A., Wu, G., \& Chau, T. (2019). A wearable fabric-based speech-generating device: System design and case demonstration. Disability \& Rehabilitation: Assistive Technology, 14(5), 434-444. https:// doi.org/10.1080/17483107.2018.1462860

Ganz, J. B., \& Simpson, R. L. (2004). Effects on communicative requesting and speech development of the picture exchange communication system in children with characteristics of autism. Journal of Autism and Developmental Disorders, 34(4), 395-409. https://doi.org/10.1023/B:JADD.0000037416.59095. d7

Herbert, M. E., Brock, M. E., Barczak, M. A., \& Anderson, E. J. (2020). Efficacy of peer-network interventions for high school students with severe disabilities and complex communication needs. Research and Practice for Persons with Severe Disabilities, 45(2), 98-114. https://doi. org/10.1177/1540796920904179

Hughes, C., Bernstein, R. T., Kaplan, L. M., Reilly, C. M., Brigham, N. L., Cosgriff, J. C., \& Boykin, M. P. (2013). Increasing conversational interactions between verbal high school students with autism and their peers without disabilities. Focus on Autism and Other Developmental Disabilities, 28(4), 241-254. https://doi.org/10.1177/1088357613487019

Hui, N., Vickery, E., Njelesani, J., \& Cameron, D. (2018). Gendered experiences of inclusive education for children with disabilities in West and East Africa. International Journal of Inclusive Education, 22(5), 457-474. https://doi.org/10.1080/13603116.2017.1370740

Hunt, P., Soto, G., Maier, J., Muller, E., \& Goetz, L. (2002). Collaborative teaming to support students with augmentative and alternative communication needs in general education classrooms. Augmentative and Alternative Communication, 18(1), 20-35. https://doi.org/10.1080/aac.18.1.20.35

Iacono, T., Douglas, S. N., Garcia Melgar, A., \& Goldbart, J. (2022). A scoping review of AAC research conducted segregatedschool settings. Research in Developmental Disabilities, 120, 104141. https:// doi.org/10.1016/j.ridd.2021.104141 
Iacono, T., Goldbart, J., Douglas, S., \& Garcia Melgar, A. (2018). The effectiveness of AAC in supporting inclusive schooleducation. PROSPERO: International prospective register of systematic reviews. https://www.crd.york.ac.uk/prospero/display_record.php?RecordID=107225

Iacono, T., Keeffe, M., Kenny, A., \& McKinstry, C. (2019). A document review of exclusionary practices in the context of Australian school education policy. Journal of Policy and Practice in Intellectual Disabilities, 16(4), 264-272. https://doi.org/10.1111/jppi.12290

Inclusion International (2009). Better education for all: When we're included too. A global report. http:// inclusion-international.org/better-education-for-all/

Johnson, J. W., \& McDonnell, J. (2004). An exploratory study of the implementation of embedded instruction by general educators with students with developmental disabilities. Education and Treatment of Children, 27(1), 46-63

Kravits, T. R., Kamps, D. M., Kemmerer, K., \& Potucek, J. (2002). Brief report: Increasing communication skills for an elementary-aged student with autism using the Picture Exchange Communication System. Journal of Autism and Developmental Disorders, 32(3), 225-230. https://doi.org/10.102 3/A:1015457931788

McSheehan, M., Sonnenmeier, R. M., Jorgensen, C. M., \& Turner, K. (2006). Beyond communication access: Promoting learning of the general education curriculum by students with significant disabilities. Topics in Language Disorders, 26(3), 266-290

Mirenda, P. (2014). Revisiting the mosaic of supports requried for including people with severe intellectual or developmental disabilities in their communities. Augmentative and Alternative Communication, 30(1), 19-27. https://doi.org/10.3109/07434618.2013.875590

Moher, D., Liberati, A., Tetzlaff, J., Altman, D. G., \& The PRISMA Group. (2009). Preferred reporting items for systematic reviews and meta-analyses: the PRISMA statement. PLoS Medicine, 6(7), e1000097. https://doi.org/10.1371/journal.pmed.1000097

Østvik, J., Ytterhus, B., \& Balandin, S. (2018). Gateways to friendships among students who use AAC in mainstream primary school. Scandinavian Journal of Disability Research, 20(1), 92-101. https://doi. org/10.16993/sjdr.51

Pace, R., Pluye, P., Bartlett, G., Macaulay, A. C., Salsberg, J., Jagosh, J., \& Seller, R. (2012). Testing the reliability and efficiency of the pilot mixed methods appraisal tool (MMAT) for systematic mixed studies review. International Journal of Nursing Studies, 49(1), 47-53. https://doi.org/10.1016/j. ijnurstu.2011.07.002

Pluye, P., Robert, E., Cargo, M., Bartlett, G., O’Cathain, A., Griffiths, F., \& Rousseau, M. C. (2011). Proposal: A mixed methods appraisal tool for systematic mixed studies reviews. http://mixedmethodsappraisaltoolpublic.pbworks.com

Reichle, J., \& Karlan, G. (1985). The selection of an augmentative system in communication intervention: A critique of decision rules. Journal of the Association for Persons with Severe Handicaps, 10, $146-156$

Schneider, N., \& Goldstein, H. (2010). Using social stories and visual schedules to improve socially appropriate behaviors in children with autism. Journal of Positive Behavior Interventions, 12(3), 149-160. https://doi.org/10.1177/1098300709334198

Shakespeare, T. (2018). Disability: The basics. Routledge

Sharma, U., Armstrong, A. C., Merumeru, L., Simi, J., \& Yared, H. (2019). Addressing barriers to implementing inclusive education in the pacific. International Journal of Inclusive Education, 23(1), 65-78. https://doi.org/10.1080/13603116.2018.1514751

Simpson, K., Beukelman, D., \& Sharpe, T. (2000). An elementary student with severe expressive communication impairment in a general education classroom: Sequential analysis of interactions. Augmentative and Alternative Communication, 16(2), 107-121

Simpson, L. A., \& Bui, Y. (2016). Effects of a peer-mediated intervention on social interactions of students with low-functioning autism and perceptions of typical peers. Education and Training in Autism and Developmental Disabilities, 51(2), 162-178

Stoner, J. B., Angell, M. E., \& Bailey, R. L. (2010). Implementing augmentative and alternative communication in inclusive educational settings: A case study. Augmentative and Alternative Communication, 26(2), 122-135. https://doi.org/10.3109/07434618.2010.481092

Sundqvist, A., Plejert, C., \& Ronnberg, J. (2010). The role of active participation in interaction for children who use augmentative and alternative communication. Communication \& Medicine, 7(2), 165-175. https://doi.org/10.1558/cam.v7i2.185 
Tricco, A., Lillie, E., Zarin, W., O’Brien, K., Colquhoun, H., Levac, D. ... Straus, S. (2018). Prisma extension for scoping reviews (prisma-scr): Checklist and explanation. Annals of Internal Medicine, 169(7), 467-473. https://doi.org/10.7326/M18-0850

UNESCO (2000). The dakar framework for action-education for all: Meeting our collective commitments. http://unesdoc.unesco.org/images/0012/001211/121147e.pdf

UNESCO (2015). Education 2030: Incheon declaration and framework for action for the implementation of sustainable development goal 4. https:/unesdoc.unesco.org/ark:/48223/pf0000233137.locale=en

UNICEF (2012). The right of children with disabilities to education: A rights-based approach to inclusive education.https://www.unicef.org/ceecis/UNICEF_Right_Children_Disabilities_En_Web.pdf

United Nations (2006). The Convention on the Rights of Persons with Disabilities.http://www.un.org/esa/ socdev/enable/rights/convtexte.htm

Wehmeyer, M. L., Shogren, K. A., \& Kurth, J. (2020). The state of inclusion with students with intellectual and developmental disabilities in the United States. Journal of Policy and Practice in Intellectual Disabilities. Advance online publication. https://doi.org/10.1111/jppi.12332

White, G., Thomas, J., Weldon, P., Lawrence, A., Galatis, H., \& Tyndall, J. (2013). Grey literature in Australian education. The Grey Journal, 9(2), 103-108

Wu, Y., Chen, M., Lo, Y., \& Chiang, C. (2020). Effects of peer-mediated instruction with AAC on science learning and communitive responses of students with significant cognitive disabilities in Taiwan. Research and Practice for Persons with Severe Disabilities, 45(3), 178-195. https://doi. org/10.1177/1540796919900955

Publisher's Note Springer Nature remains neutral with regard to jurisdictional claims in published maps and institutional affiliations.

\section{Authors and Affiliations}

\section{Teresa lacono ${ }^{1} \cdot$ Juliet Goldbart ${ }^{2} \cdot$ Sarah N. Douglas ${ }^{3} \cdot$ Ana Garcia-Melgar $^{4}$}

Teresa Iacono

t.iacono@latrobe.edu.au

1 La Trobe University, Edwards Road, Bendigo, Victoria, Australia

2 Manchester Metropolitan University, Manchester, United Kingdom

3 Michigan State University, East Lansing, United States

4 LaTrobe University, Bendigo, Victoria, Australia 